\title{
Pintomyia (Pifanomyia) paleotownsendi, a new sand fly from the Miocene amber of Dominican Republic (Diptera: Psychodidae: Phlebotominae)
}

\author{
José Dilermando Andrade Filho, Alda Lima Falcão, Eunice A Bianchi Galati*, \\ Reginaldo Peçanha Brazil**/+
}

\begin{abstract}
Laboratório de Leishmanioses, Centro de Pesquisas René Rachou-Fiocruz, Belo Horizonte, MG, Brasil *Departamento de Epidemiologia, Faculdade de Saúde Pública, Universidade de São Paulo, São Paulo, SP, Brasil **Departamento de Bioquímica e Biologia Molecular, Instituto Oswaldo Cruz-Fiocruz, Av. Brasil 4365, 21045-900 Rio de Janeiro,RJ, Brasil
\end{abstract}

Phlebotominae includes some vector species, mainly that of leishmaniases, with a very old host-parasite relationship. Some species fossils of this subfamily have been recently described and this paper presents the description of a new sand fly Pintomyia (Pifanomyia) paleotownsendi sp. nov in amber. The gonostyle present four spines, being one apical, one external superior implanted close to the apical third, one external inferior in the middle of the structure and one internal implanted in the basal third. This disposition of the spines may separate the new species from others in the sub genus.

Key words: Pintomyia paleotownsendi - amber - fossil - Phlebotominae

Phlebotominae includes some vector species, mainly that of leishmaniases, with a very old host-parasite relationship (Poinar Jr \& Poinar 2004). Some fossils species of this subfamily have been described (Brazil \& Andrade Filho 2002, Andrade Filho \& Brazil 2003, Andrade Filho et al. 2006). The specimen in question is preserved in amber, a vegetal resin, which conserves the morphological characteristics necessary for its study. This amber measuring $12 \mathrm{~mm}$ long $\times 6 \mathrm{~mm}$ wide $\times 2 \mathrm{~mm}$ high, allows to observe the thoracic and the male genital structures under microscope $(400 \times)$ and the head $(100 \times)$.

The fly was measured using an Olympus $\mathrm{CH}-2$ optical microscope and drawing in a clear chamber adapted to the microscope. A digital photograph was taken with a camera attached to the Olympus microscope (Fig. 1) and another digitalized using a microscope Zeiss attached to a computer using program KS300 (Fig. 2).

The proposed classification is that of Galati (2003) and nomenclature of structures of McAlpine (1981). Measurements are given in micrometers.

The new species named Pintomyia paleotownsendi sp. nov., in reference to the similarity to the type $P$. townsendi (Ortiz, 1959) of series townsendi.

Pintomyia (Pifanomyia) paleotownsendi $\mathrm{sp}$. nov

Holotype male (Figs 1, 2, 3)

Head: laid on its side, but this measurement is possible, with 278 of length by 222 width. Ratio clypeus/head 0.36:1. Labrum-epipharynx 122 length, ratio labrum- epipharynx/head 0.44:1. Palpal formula 1.4.2.3.5, measuring 1st-33; 2nd-100; 3rd-111; 4th-89; 5th-244. Newstead's spine implanted disperse in the third palpomere. Antennae with ascoids and papillae not visible. Measurements of the principal flagellomeres: AIII-189; AIV-100; AV-94. AXV longer than AXVI.

Thorax: wing 1465 long with 389 width. Principal wing indices: alpha-255; beta-189; gama-200; delta-22, and R5899. Legs without special character. Anterior, median and posterior femora measuring 644,522 , and 611 , respectively. Anterior, median and posterior tibiae measuring 710, 755, and 955 , respectively and anterior, median and posterior tarsomere with 389, 488, and 533, respectively.

Abdomen: genital pump not visible. Gonostyle 78 long, with four spines: one apical, the external superior implanted close to the apical third, the external inferior in the middle of the structure and the internal one in the basal third.

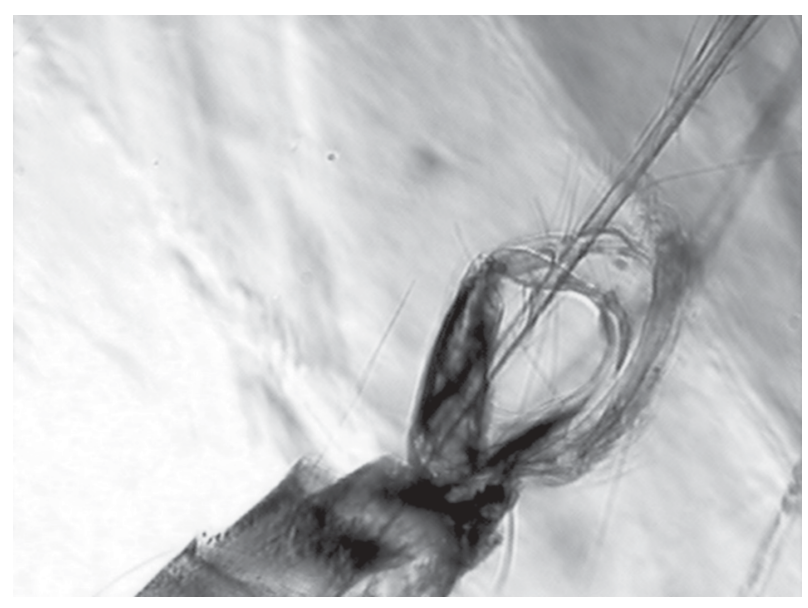

Fig. 1: Pintomyia (Pifanomyia) paleotownsendi sp. nov. in Dominican amber. Male genitalia 400x. 


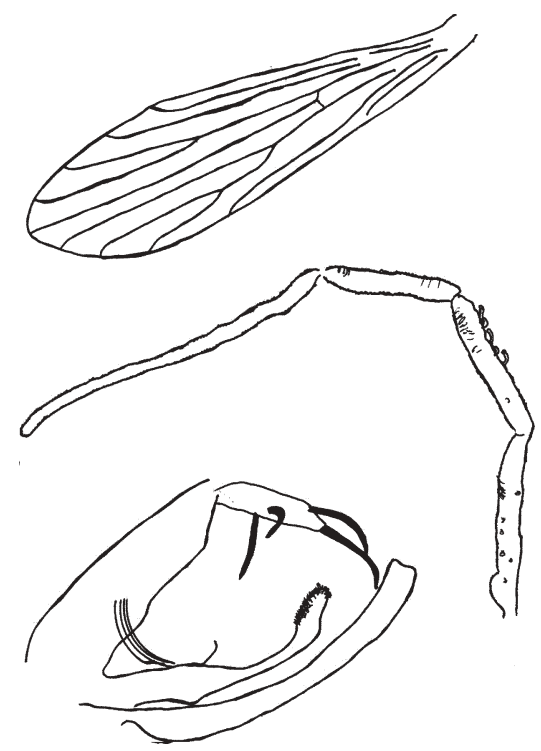

Fig. 2: Pintomyia (Pifanomyia) paleotownsendi sp. nov. Drawing of the genitalia, palp, and wing.

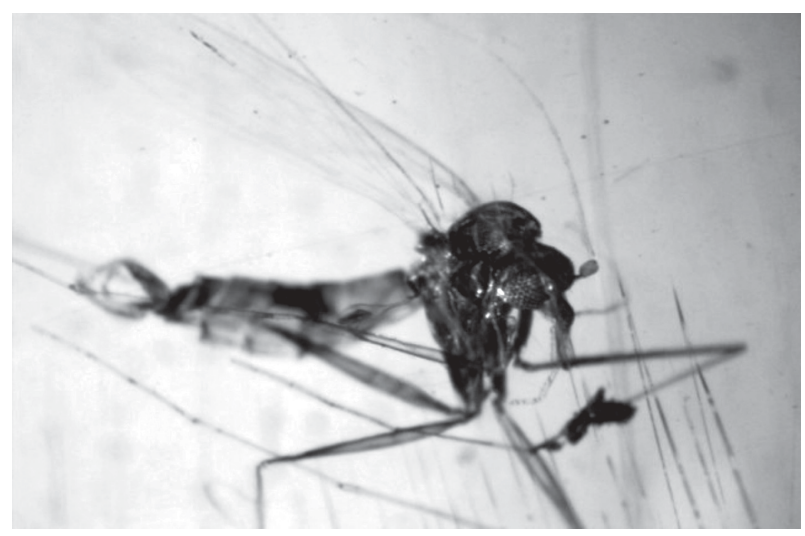

Fig. 3: Pintomyia (Pifanomyia) paleotownsendi sp. nov. in amber, holotype male, $200 \times$.

Gonocoxite 182 long by 44 width, presents a central tuft with about five thin setae. Paramere 222 length, has a dorsal curvature in its apex, where it presents a group of small setae and also a short spine in its basal third. Lateral lobe longer than the gonocoxite.

Type material: holotype, Dominican Republic, north Santiago, specimen in amber from the mid-Miocene period, deposited in the phlebotomine sand fly collection of the Centro de Pesquisas René-Rachou (Fundação Oswaldo Cruz), Belo Horizonte, MG, Brazil

\section{REMARKS}

All caracters described above allow us to include this new species within the genus Pintomyia, sub genus Pifanomyia and townsendi series.

The disposition of spines in the gonostyle separates with security $P .(P$.$) paleotownsendi from the other spe-$ cies in the townsendi series, that have an internal spine in the basal 5th of the style while in this new species this spine is situated in the basal 3rd. Only one species in the townsendi series; Pintomyia nuneztovari (Ortiz, 1959) does not have the spine implanted as described above however the new species is clearly distinguished from $P$. nuneztovari by a dorsal curvature of the paramere apex.

Up to now this species is the only fossil sand fly from Dominican Republic with a tuft of setae in the gonacoxite in contrast with other described fossil species without tuft of setae (Brazil \& Andrade Filho 2002, Andrade Filho et al. 2004, 2006).

\section{ACKNOWLEDGEMENTS}

To Beatriz Gomes Brazil for critical review of the manuscript.

\section{REFERENCES}

Andrade Filho JD, Brazil RP 2003. Relationships of new word phlebotomine sand flies (Diptera: Psychodidae) based on fossil evidence. Mem Inst Oswaldo Cruz 98 (Suppl. 1): 145-149.

Andrade Filho JD, Falcão AL, Brazil RP 2004. A new phlebotomine fossil species Trichopygomyia killickorum $\mathrm{sp} . \mathrm{n}$. (Diptera: Psychodidae), found in the Dominican Republic amber. Parasite 11: 71-73.

Andrade Filho JD, Galati EAB, Falcão AL 2006. Description of Pintomyia (Pifanomyia) brazilorum sp. nov. a new fossil species from the Dominican Republic (Diptera: Psychodidae: Phlebotominae). Mem Inst Oswaldo Cruz (in press).

Brazil RP, Andrade Filho JD 2002. Description of Pintomyia (Pifanomyia) falcaorum sp. n. (Diptera: Psychodidae: Phlebotominae), a fossil sand fly from Dominican Amber. Mem Inst Oswaldo Cruz 97: 501-503.

Galati EAB 2003. Classificação de Phlebotominae. In EF Rangel, R Lainson (eds), Flebotomíneos do Brasil, Fiocruz, Rio de Janeiro, p. 23-51.

McAlpine JF 1981. Morphology and terminology - Adults. In JF McAlpine, BV Peterson, GE Shelwell, HJ Teskey, JR Vockeroth, DM Wood (eds), Manual of Nearctic Diptera, Ottawa, Research Branch Agriculture Canada, Monography 27,Vol. 1, p. 9-63.

Poinar Jr G, Poinar R 2004. Paleoleishmania proterus n. gen., n. sp., (Trypanosomatidae: Kinetoplastida) from cretaceous burmese amber. Protist 155: 305-310. 